\title{
Permeation of Herbicidal Dichlobenil From a Casoron Formulation Through Nitrile Gloves
}

\author{
Shane S. Que Hee • Hanaa Zainal
}

Received: 17 August 2009/Accepted: 28 September 2009/Published online: 24 October 2009

(C) The Author(s) 2009. This article is published with open access at Springerlink.com

\begin{abstract}
The aim of this study was to measure permeation of the herbicide dichlobenil in Casoron 4G through disposable and chemically protective nitrile gloves using an American Society for Testing and Materials-type permeation cell and a closed-loop system employing two different solvents (hexane and water) and two different challenge situations (aqueous emulsion and solid formulation). Capillary gas chromatography-mass spectrometry was used for quantification purposes. The chemically protective glove did not allow any permeation up to $8 \mathrm{~h}$ for the solid-formulation and water-collection challenges, but permeation was detected in all other challenges. The disposable glove allowed the most permeation, and the solidformulation challenge with water collection necessitated that a dichlobenil equivalent be calculated because of the presence of its hydrolysis degradation product 2,6-dichlorobenzamide. Permeation from the solid formulation was detectable by hexane collection for both the disposable and chemically protective gloves and by water collection for the disposable glove. It was concluded that hexane-solvent collection was not valid for the disposable glove at 4 and 8 $\mathrm{h}$ of permeation in the solid Casoron challenge or for the aqueous emulsion challenge at $8 \mathrm{~h}$ relative to the watercollection solvent data. The hexane-solvent collection for the chemically protective glove was valid for the 8-h solidformulation challenge but not for the 8-h aqueous-solution
\end{abstract}

\section{S. S. Que Hee $(\bowtie) \cdot$ H. Zainal}

Department of Environmental Health Sciences and UCLA Center for Occupational and Environmental Health, School of Public Health, University of California at Los Angeles, 650 Charles Young Jr Drive South, Los Angeles, CA 90095-1772, USA

e-mail: squehee@ucla.edu challenge. All water-solvent collections were valid; however, dichlobenil usually permeated the gloves.

Dichlobenil (2,6-dichlorobenzonitrile; Chemical Abstracts Service RN 1194-65-6) is a nonselective systemic soil herbicide applied for pre- and post-emergence weed control in many fruits and flowers as well as in slow-flowing aquatic systems (Hazardous Substances Data Bank 2009). Its major human effects are dermatitis, chloracne, and nasal tissue attack (involving necrosis of the dorsomedial part of the olfactory neuroepithelium with permanent damage to the underlying mucosa [independent of the mode of exposure]). Because exposed rodents developed liver tumors, the United States Environmental Protection Agency (USEPA) has classified dichlobenil as a group $\mathrm{C}$ carcinogen (possible human carcinogen). It is volatile (vapor pressure approximately $6.6 \times 10^{-4} \mathrm{~mm} \mathrm{Hg}$ at $\left.20^{\circ} \mathrm{C}\right)$, is moderately soluble in water $\left(18 \mathrm{ppm}\right.$ at $\left.20^{\circ} \mathrm{C}\right)$, and has a moderate $\log \mathrm{pK}_{\mathrm{OW}}$ value of 2.74. Although there are no occupational guidelines, the USEPA in 2008 established combined tolerances for dichlobenil and its metabolite 2,6-dichlorobenzamide on specific crops ranging from 0.06 to $0.15 \mathrm{ppm}$, although the amide is also a metabolite of the herbicide fluopicolide (USEPA 2008). The acceptable daily intake is $500 \mathrm{ng} / \mathrm{kg}$ body weight (Hazardous Substances Data Bank 2009).

No scientific literature has been published on the permeation of dichlobenil through glove materials, which are the chief mode of protection of hand skin. A common message in many material safety data sheets for formulations containing dichlobenil, without specifying the glove material, is to "use chemical resistant protective gloves," "wear suitable protective equipment," or "wear protective clothing." Regarding the emulsifiable concentrates of pesticides, i.e., 
Casoron CS for dichlobenil, handling, spraying, and formulating the liquid concentrate are probably the most hazardous operations because many chemicals are involved at high concentrations in often quasi-confined unventilated spaces. Worker field re-entry to wet foliage and soil after spraying is another hazardous scenario that has generally been mitigated by respecting the correct re-entry interval. Many pesticides are available in dust form, e.g., Casoron G, G-2, G-4, and 4G for dichlobenil; thus, inhalation protection for particulates may also be needed. We provide here the first reported quantitative permeation of dichlobenil through specific glove materials.

\section{Experiment}

\section{Materials}

Casoron 4G (4.0\% dichlobenil) came from Chemtura (Middlebury, CT). The granular formulation also contained an unspecified thickening agent and a proprietary carrier at unspecified concentrations. The recommended application range is $50-300 \mathrm{lb} /$ acre $(56-340 \mathrm{~kg} / \mathrm{ha})$; the re-entry interval is $12 \mathrm{~h}$. Pure dichlobenil (99.5\% purity nominally), 2,6-dichlorobenzamide (99\% purity nominally), and internal standard (IS) 4,4'-dichlorobiphenyl (99\%) were obtained from ChemService (West Chester, PA). Optimagrade hexanes (hereafter called hexane) and isopropanol came from Fisher Scientific (Pittsburgh, PA). All water was Millipore triple-cartridge deionized.

Safeskin nitrile powder-free examination gloves $(24.1-\mathrm{cm}$ length, unspecified thickness, no. N330; Kimberly Clark, San Diego, CA) were obtained from Fisher Scientific. Solvex unsupported and unlined nitrile chemical protective gloves (33-cm length, 11-mil thickness, No. 37-145) came from Ansell Occupational Healthcare (Coshocton, $\mathrm{OH}$ ).

\section{Equipment}

A calibrated Marathon electronic digital micrometer (model No. CO 030025, 0-25 mm range, $0.001 \mathrm{~mm}$ resolution; Fisher) was used to measure glove thickness before and after permeation testing. A calibrated Mettler analytic balance delta range (model No. AE260; Mettler, Hightstown, NJ) was used to weigh gloves before and after permeation.

Infrared (IR) spectra were obtained with an Avatar 360 Fourier-transform (FT) spectrophotometer system (ThermoNicolet, Madison, WI) and a single-beam FT-IR spectrophotometer using the reflectance mode and operated with OMNIC 6.0a software. The crystal was diamond in single-reflection horizontal attenuated total reflectance mode. The spectral range was $4,000-600 \mathrm{~cm}^{-1}$, and the number of scans was 64 .
Gas chromatography-mass spectrometry (GC-MS) was performed with an Agilent $6890 \mathrm{~N}$ network gas chromatograph (Agilent Technologies, Wilmington, DE) connected to an Agilent 5973 network mass selective detector (MSD). The MSD was a quadrupole with an electron multiplier detector. The GC column was an HP 5-MS $30 \mathrm{~m} \times 0.25 \mathrm{~mm}$ i.d. $(0.25-\mu \mathrm{m}$ film) fused silica capillary column (Agilent). The helium carrier flow (99.9999\%; Air Liquide, Long Beach, CA) was $3.00 \pm 0.20 \mathrm{~mL} / \mathrm{min}$. The temperature of the injector was $200^{\circ} \mathrm{C}$ and that of the transfer line was $280^{\circ} \mathrm{C}$. The $70-\mathrm{eV}$ ion source and the quadrupole were held at $230^{\circ}$ and $150^{\circ} \mathrm{C}$, respectively.

Water and Hexane Solubility of Dichlobenil

A mass of $10 \mathrm{mg}$ dichlobenil was mixed with $20 \mathrm{~mL}$ water in a brown centrifuge tube in triplicate. Each sample was sonicated at $40^{\circ} \mathrm{C}$ for $60 \mathrm{~min}$ with the screw cap on. After cooling to $22.5^{\circ} \mathrm{C}$, the solution was centrifuged at $900 \mathrm{~g}$ for $30 \mathrm{~min}$; $0.2 \mathrm{~mL}$ of the supernatant fraction was transferred to a $4-\mathrm{mL}$ vial; this was extracted consecutively with $0.4,0.3$, and $0.3 \mathrm{~mL}$ hexane; and the extracts were combined for analysis. The IS 4,4'-dichlorobiphenyl in hexane was added to a final concentration of $0.5 \mathrm{ng} / \mathrm{mL}$. The amount of dichlobenil was determined by GC-MS using the IS method (see later text). The solubility was then calculated. A similar procedure was performed to determine dichlobenil solubility in hexane.

\section{Dichlobenil Content of Casoron $4 \mathrm{G}$ and Stability in} Solvents

A $2 \mathrm{mg} / \mathrm{mL}$ solution of Casoron $4 \mathrm{G}$ was prepared separately in hexane, isopropanol, and water. A subvolume of $0.1 \mathrm{~mL}$ was then diluted to $1 \mathrm{~mL}$ with hexane and isopropanol, as appropriate, for direct analysis by the IS method (see later text). The $0.1-\mathrm{mL}$ water solution was brought just to dryness in a stream of nitrogen and dissolved to produce $1 \mathrm{~mL}$ isopropanol solution for GC-MS analysis (see later text).

Aqueous solutions containing $1 \mathrm{~g}$ Casoron $4 \mathrm{G}$ in $25 \mathrm{~mL}$ volumetric flasks were also sonicated for $1 \mathrm{~h}$ at $40^{\circ} \mathrm{C}$ and filtered the next day. Then $0.1 \mathrm{~mL}$ filtrate was evaporated as previously described. The residue was dissolved in isopropanol and then analyzed using the total ion current mode $(\mathrm{m} / \mathrm{z}, 50-550)$ of the GC-MSD to allow hydrolysis products to be identified and quantified.

\section{Permeation Procedure}

The permeation procedure was based on a modified American Society for Testing and Materials (ASTM) F73999a permeation method (2004). Out-of-the-box gloves were conditioned for $24 \mathrm{~h}$ in a desiccator, in which the relative humidity was maintained at $55 \% \pm 1 \%$ by 
saturated aqueous sodium dichromate, as recommended by the ASTM method. Circular pieces, $42.5 \mathrm{~mm}$ in diameter, were cut from the palm area of six gloves of each glove type. Just before permeation, glove thickness was measured using six random readings, and the arithmetic means and SDs were calculated. The gloves were then weighed. The IR reflectance spectrum of the material near the cut piece was then measured at a specific clamp pressure.

Each circular piece was then held between the two Teflon gaskets/Pyrex chambers of an I-PTC-600 ASTMtype permeation cell (Pesce Laboratory, Kennett Square, PA) by a uniform torque with the outer surface of the glove facing the challenge chamber. The exposed glove material between the two chambers was $25.4 \mathrm{~mm}$ in diameter. A $10-\mathrm{mL}$ volume of aqueous emulsion at a concentration of $2.0 \mathrm{mg} / \mathrm{mL}$ was pipetted into the challenge chamber, and $10 \mathrm{~mL}$ solvent (hexane or water) was pipetted into the collection chamber. Solid Casoron 4G powder (8.500 g) was placed in the challenge side for some challenges.

The permeation cells were clamped and immersed six at a time in a Fisher shaking water bath (model 127) at $35.0^{\circ} \mathrm{C} \pm 0.5^{\circ} \mathrm{C}$ so that the test material in each cell was vertical. The permeation cells were agitated for $8 \mathrm{~h}$ at an average horizontal shaking speed of $70 \pm 5$ cycles/min; the traveling distance was $10.24 \mathrm{~cm} /$ cycle. This assured that the emulsion did not stratify, that the collection side did not build up concentration gradients, and that the test material was wetted continuously on both sides. The collection solvent and the challenge solution were then weighed. The permeation cells were disassembled, and the outer surfaces of glove pieces were blotted dry with Kimwipes. The glove pieces were reconditioned in a desiccator for $24 \mathrm{~h}$ before final weight, thickness, and IR reflectance measurements were taken.

Solvent blank tests with $10 \mathrm{~mL}$ solvent in the collection chamber, with only air in the challenge chamber, were also performed. Information on back-permeation of the collection chamber solvent was obtained by injecting challengechamber air samples in gas-tight syringes into the GC-MS. All tests were performed at least in triplicate.

\section{Quantitation of Dichlobenil After Permeation}

The collection and challenge aqueous solutions were evaporated just to dryness under a flow of nitrogen at $40^{\circ} \mathrm{C}$ in a volumetric tube. A volume of $50 \mu \mathrm{L} 100 \mu \mathrm{g} / \mathrm{mL} 4,4^{\prime}$ dichlorobiphenyl IS in hexane was added, and hexane was added to a final volume of $1.0 \mathrm{~mL}$. A $2-\mu \mathrm{L}$ aliquot was injected into the GC-MS for analysis. The final IS concentration in the injection was $0.5 \mu \mathrm{g} / \mathrm{mL}$.

The MS detected ions of mass-to-charge ratio $(\mathrm{m} / \mathrm{z})$ 171,173 , and 222 in the selected ion monitoring mode. In some runs, the total ion current mode with $\mathrm{m} / \mathrm{z}$ 50-550 was used for identification purposes. The GC column was operated isothermally at $100^{\circ} \mathrm{C}$ for $2 \mathrm{~min}$, heated at $20^{\circ} \mathrm{C} /$ min to $200^{\circ} \mathrm{C}$, and the temperature maintained at $200^{\circ} \mathrm{C}$ for $30 \mathrm{~min}$ at $2.5 \mathrm{~mL} / \mathrm{min}$; the solvent delay was $2.0 \mathrm{~min}$. Each run took $35 \mathrm{~min}$ to complete.

Ratios of dichlobenil area for $m / z, 171$ over IS area for $m / z 222$ in the chromatograms were plotted versus corresponding dichlobenil mass injected to provide the calibration curve for dichlobenil. For analyses involving 2,6-dichlorobenzamide, $m / z 189$ was also monitored as was $m / z$ 173. It should be noted that $m / z 173$ is $(\mathbf{M}+2)^{+}$associated with the $\mathrm{m} / z 171$ molecular ion $\left(\mathrm{M}^{+}\right)$for dichlobenil and is also the base ion $(\mathrm{M}-16)^{+}$for 2,6-dichlorobenzamide. The linear portion was determined and subjected to linear regression to calculate the slope and intercept, their SDs, the correlation coefficient $r$, and the $p$ value.

FT reflectance IR scan analysis of the dry glove materials was performed from 4,000 to $600 \mathrm{~cm}^{-1}$. The major reflectance maxima for dichlobenil at 782, 1198, and $1431 \mathrm{~cm}^{-1}$ and those for 2,6-dichlorobenzamide at 1643 and $787 \mathrm{~cm}^{-1}$ were scrutinized.

\section{Results and Discussion}

\section{Calibration Data}

The GC-MS linear range for dichlobenil using $m / z 171$ at a retention time of approximately $5.0 \mathrm{~min}$ by the IS method was $0.03-6 \mathrm{ng}$; similarly, that for 2,6-dichlorobenzamide using $\mathrm{m} / \mathrm{z}, 173$ at a retention time of approximately $7.1 \mathrm{~min}$ was $0.025-0.3 \mathrm{ng}$. Typical $r$ values were $>0.9990$. The IS 4,4'-dichlorobiphenyl $(\mathrm{m} / \mathrm{z}, 222)$ had a retention time of approximately $8.0 \mathrm{~min}$.

\section{Dichlobenil Water Solubility and Stability in Water and} Hexane

The water-solubility triplicate results were 20.4, 18.9, and $23.1 \mathrm{mg} / \mathrm{L}$ to provide an arithmetic mean and $\mathrm{SD}$ of $20.8 \pm 2.1 \mathrm{mg} / \mathrm{L}$ at $22.5^{\circ} \mathrm{C}$. The literature solubility value at $20^{\circ} \mathrm{C}$ is $18 \mathrm{mg} / \mathrm{L}$ (Hazardous Substances Data Bank 2009). There is adequate agreement at $p \leq 0.05$. The solubility at a specific temperature sets the upper concentration that a water collection vehicle can attain in the absence of adjuvants.

The experiment to test the stability of Casoron $4 \mathrm{G}$ in hexane and isopropanol resulted in no degradation to the amide. The water solution, analyzed when fresh, also showed no degradation, but the solution that was ultrasonicated at $40^{\circ} \mathrm{C}$ for $1 \mathrm{~h}$, left overnight, and processed on day 2 contained hydrolysis products. The chromatogram also showed the presence of lauric anhydride, probably from the pyrolysis of sodium laurate surfactant. 
Dichlobenil Content of Casoron 4G and Analytic Standard Purity

The dichlobenil contents for three replicates were (w/w) 4.1, 4.3, and 3.5\%, with an arithmetic mean and SD of $3.97 \pm 0.42 \%$. This is not significantly different from the nominal composition of $4.0 \%$ at $p \leq 0.05$. There was a trace of 2,6-dichlorobenzamide. The major impurity $(<1 \%)$ in the analytic standard was also 2,6-dichlorobenzamide. The analytic standard purity from organic solvent studies was determined to be $99.5 \pm 0.8 \%$. Dichlobenil in Casoron $4 \mathrm{G}$ was stable in isopropanol and hexane for at least 2 days. In water, 2,6-dichlorobenzamide was also produced by day 2. The $\mathrm{pH}$ of the aqueous emulsion of $2.0 \mathrm{mg} / \mathrm{mL}$ was 6.8. Basic conditions enhance hydrolysis (Hazardous Substances Data Bank 2009).

\section{Permeation}

The results, including the resultant mass/area factor and the calculated linear flux, for the two solvent collection systems and for the two different nitrile glove types are listed in Table 1 for the aqueous-emulsion challenge and in Table 2 for the solid-formulation challenge in terms of total dichlobenil permeated during $8 \mathrm{~h}$ of exposure. The latter assumes linear (steady-state) permeation kinetics but is not necessarily related to the steady-state permeation rate. Inter-run precision decreased as the permeated mass approached analytic detection limits. Shrinking or swelling of glove materials did not occur, and FT IR reflectance measurements did not detect dichlobenil on the dried inside surface of glove materials or any inner surface damage, although the herbicide was detected on the dried challenge side after permeation experiments. The sole exception for the inner surface was the solid Casoron $4 \mathrm{G}$ challenge for Safeskin with water collection, in which the 2,6-dichlorobenzamide amide stretch at $1643 \mathrm{~cm}^{-1}$ was clearly visible.

Table 1 shows that in terms of average total dichlobenil permeated at $8 \mathrm{~h}$ for Safeskin disposable gloves, hexane collected approximately 86,000 times more herbicide than water. The results of hexane and water collection disputed whether the glove can be labeled as meeting the ASTM closed-loop system criterion of $250 \mathrm{ng} / \mathrm{cm}^{2}$ for the mass/ area factor to define normalized breakthrough time (ASTM 2004). Similarly, the Solvex challenge with hexane collection allowed approximately 840 times more dichlobenil to be collected than by water, with a similar disagreement on whether the normalized breakthrough time was exceeded. In terms of how much more protective Solvex was than Safeskin for the same collection solvent, the factors were 52 for hexane and 0.51 for water. The results of the water-collection experiments for Safeskin and Solvex inferred that the normalized breakthrough time was $>8 \mathrm{~h}$ for both gloves.

Table 2 shows that the solid Casoron 4G challenge produced qualitatively the same results as the solution
Table 1 Permeation after 8-h dichlobenil exposure from Casoron $4 \mathrm{G}$ formulation at $2.0 \mathrm{mg} / \mathrm{mL}$ aqueous emulsion in the challenge side of a ASTMtype permeation cell using $10 \mathrm{~mL}$ water or hexane as collection solvent for disposable Safeskin or chemically protective Solvex nitrile gloves

${ }^{\text {a }} \mathrm{Av} \pm \mathrm{SD}$ is average

(arithmetic mean) $\pm \mathrm{SD}$

\begin{tabular}{|c|c|c|c|c|}
\hline Glove & Solvent & $\begin{array}{l}\text { Replicate } \\
\text { mass (ng) }\end{array}$ & $\begin{array}{l}\text { Mass/area } \\
\left(\mathrm{ng} / \mathrm{cm}^{2}\right)\end{array}$ & $\begin{array}{l}\text { Linear flux } \\
\left(\mathrm{ng} / \mathrm{cm}^{2} / \mathrm{min}\right)\end{array}$ \\
\hline \multirow[t]{10}{*}{ Safeskin } & Hexane & & & \\
\hline & 1 & 254,000 & 50,700 & 106 \\
\hline & 2 & 181,000 & 36,000 & 75.0 \\
\hline & 3 & 199,000 & 39,700 & 82.8 \\
\hline & $\mathrm{Av} \pm \mathrm{SD}^{\mathrm{a}}$ & $211,000 \pm 38,000$ & $42,100 \pm 7600$ & $88 \pm 16$ \\
\hline & Water & & & \\
\hline & 1 & 2.10 & 0.420 & 0.000875 \\
\hline & 2 & 2.36 & 0.472 & 0.000983 \\
\hline & 3 & 2.89 & 0.577 & 0.00120 \\
\hline & $\mathrm{Av} \pm \mathrm{SD}$ & $2.45 \pm 0.40$ & $0.490 \pm 0.080$ & $0.00102 \pm 0.00017$ \\
\hline \multirow[t]{10}{*}{ Solvex } & Hexane & & & \\
\hline & 1 & 4.310 & 861 & 0.179 \\
\hline & 2 & 4.490 & 899 & 0.187 \\
\hline & 3 & 3.340 & 668 & 0.139 \\
\hline & $\mathrm{Av} \pm \mathrm{SD}$ & $4047 \pm 620$ & $810 \pm 120$ & $0.168 \pm 0.026$ \\
\hline & Water & & & \\
\hline & 1 & 5.72 & 1.14 & 0.00238 \\
\hline & 2 & 4.12 & 0.823 & 0.00171 \\
\hline & 3 & 4.65 & 0.930 & 0.00194 \\
\hline & $\mathrm{Av} \pm \mathrm{SD}$ & $4.83 \pm 0.82$ & $0.96 \pm 0.16$ & $0.00201 \pm 0.00034$ \\
\hline
\end{tabular}


Table 2 Permeation after 8-h dichlobenil exposure from solid Casoron $4 \mathrm{G}$ formulation $(8.5 \mathrm{~g})$ in the challenge side of a ASTM-type permeation cell using $10 \mathrm{~mL}$ water or hexane as collection solvent for disposable Safeskin or chemically protective Solvex nitrile gloves
${ }^{\mathrm{a}} \mathrm{Av} \pm \mathrm{SD}$ is average (arithmetic mean) $\pm \mathrm{SD}$

b Computed from 2,6dichlorobenzamide and dichlobenil in the collection side

\begin{tabular}{|c|c|c|c|c|}
\hline Glove & Solvent & $\begin{array}{l}\text { Replicate } \\
\text { mass (ng) }\end{array}$ & $\begin{array}{l}\text { Mass/area } \\
\left(\mathrm{ng} / \mathrm{cm}^{2}\right)\end{array}$ & $\begin{array}{l}\text { Linear flux } \\
\left(\mathrm{ng} / \mathrm{cm}^{2} / \mathrm{min}\right)\end{array}$ \\
\hline \multirow[t]{10}{*}{ Safeskin } & \multicolumn{4}{|l|}{ Hexane } \\
\hline & 1 & 642,000 & 128,000 & 268 \\
\hline & 2 & $1,120,000$ & 225,000 & 468 \\
\hline & 3 & 755,000 & 151,000 & 314 \\
\hline & $\mathrm{Av} \pm \mathrm{SD}^{\mathrm{a}}$ & $839,000 \pm 250,000^{b}$ & $168,000 \pm 51,000$ & $350 \pm 100$ \\
\hline & \multicolumn{4}{|l|}{ Water } \\
\hline & 1 & 32.3 & 6.47 & 0.0135 \\
\hline & 2 & 30.0 & 5.20 & 0.0108 \\
\hline & 3 & 20.4 & 4.08 & 0.0085 \\
\hline & $\mathrm{Av} \pm \mathrm{SD}$ & $27.6 \pm 6.3^{b}$ & $5.3 \pm 1.2$ & $0.0109 \pm 0.0025$ \\
\hline \multirow[t]{10}{*}{ Solvex } & \multicolumn{4}{|l|}{ Hexane } \\
\hline & 1 & 447 & 89.4 & 0.186 \\
\hline & 2 & 179 & 35.8 & 0.0746 \\
\hline & 3 & 369 & 73.7 & 0.154 \\
\hline & $\mathrm{Av} \pm \mathrm{SD}$ & $330 \pm 140$ & $66 \pm 28$ & $0.138 \pm 0.057$ \\
\hline & \multicolumn{4}{|l|}{ Water } \\
\hline & 1 & $<3$ & $<0.6$ & $<0.0012$ \\
\hline & 2 & $<3$ & $<0.6$ & $<0.0012$ \\
\hline & 3 & $<3$ & $<0.6$ & $<0.0012$ \\
\hline & $\mathrm{Av} \pm \mathrm{SD}$ & $<3$ & $<0.6$ & $<0.0012$ \\
\hline
\end{tabular}

challenges, that is, Solvex always protected better than Safeskin, and water collection always resulted in lower collected amounts than hexane collection. Compared with water collection, hexane collected approximately 30,000 times more dichlobenil for Safeskin disposable gloves and approximately $>110$ times more dichlobenil for Solvex gloves. In terms of how much more protective Solvex was than Safeskin for the same collection solvent, the factors were approximately 2,500 for hexane and $>10$ times for water. The results of the water-collection experiments for Safeskin and Solvex inferred that the normalized breakthrough time was $>8 \mathrm{~h}$ for both gloves, and only for Solvex did both hexane- and water-collection data agree that the normalized breakthrough time had not been exceeded. We also performed a 4-h permeation experiment for hexane collection with solid Casoron for Safeskin. The triplicates for mass permeated yielded the following results: 190, 189, and $234 \mu \mathrm{g}(204 \pm 26)$. Similarly, the average mass/area factor was $40,900 \pm 5,100 \mathrm{ng} / \mathrm{cm}^{2}$, and the average linear flux was $170 \pm 22 \mathrm{ng} / \mathrm{cm}^{2} / \mathrm{min}$. Clearly, the normalized breakthrough time for Safeskin with hexane collection for this solid-formulation challenge was $<4 \mathrm{~h}$. For Safeskin and Solvex challenged by solid Casoron, the form of dichlobenil detected in the water-collection system was mostly 2,6-dichlorobenzamide, with minor dichlobenil observed, necessitating the quantification of both to obtain a dichlobenil equivalent. This did not occur in the aqueous emulsion challenge liquid and hexane collections. The components of the formulation must stabilize dichlobenil in aqueous emulsion.

Our experimental water solubility of dichlobenil of $20.8 \mathrm{mg} / \mathrm{L}$ is equivalent to a $10-\mathrm{mL}$ collection solution containing an analyte mass of $208 \mu \mathrm{g}$. No water-collection solution contained this amount of dichlobenil at the end of the permeation period, although this volume of water had such a capacity. It is possible that water is so polar that strong adsorption to the glove surface may not render the permeated herbicide available enough for solubilization from the collection side surface. Any tightly adsorbed permeate would decrease the permeation rate through the membrane and produce a negative bias to the observed concentration in water. In addition, glove manufacturer data show that the normalized breakthrough time of hexane for Safeskin is approximately $21 \mathrm{~min}$ (Reyes 2002). Solvex does not break through within $480 \mathrm{~min}$ for hexane (Ansell Occupational Healthcare 2007). The validity of the liquid-collection method depends on the solvent being inert to the glove and yet being able to solubilize the analyte. The solvent must prevent a concentration gradient from occurring at the water-surface interface because only permeation through the material is of interest.

Another interesting result is that nitrile challenge with dry Casoron $4 \mathrm{G}$ powder produces the same generalized results as aqueous emulsion challenges, with higher levels of dichlobenil permeated for Safeskin but not for Solvex gloves. Thus, at $8 \mathrm{~h}$ for Safeskin gloves, the ratios for 
solid-to-aqueous solution dichlobenil ratio data for water and hexane were approximately 11 and 4 , respectively. The corresponding data for Solvex gloves are $<0.62$. and 0.82, respectively, thus reflecting the general protectiveness of Solvex gloves.

The phenomenon of organic solids producing permeation across glove material was first observed by Fricker and Hardy $(1992,1994)$, who used a modification of the ASTM permeation cell. Other such data have been published by Bunge and others for methylparaben and 4-cyanophenol (Parks et al. 1997; McCarley and Bunge 2003; Romonchuk and Bunge 2006; Ley and Bunge 2007). The mechanism to explain the results of the present study probably involves the collection medium wetting the material enough to backpermeate to the challenge surface or the production of a wet membrane interior from which some solid is dissolved to then diffuse back to the collection medium compartment. Another possibility is the presence of microholes in the glove material that constitutes a penetration component, but such microholes were not observed by microscopic observation in any of the materials examined. Back-permeation experiments with an empty challenge side showed that Safeskin gloves allowed hexane vapor to be detected in the challenge chamber air, but Solvex gloves did not.

Relative to worker risk assessment for dichlobenil exposure, the allowed daily intake of $500 \mathrm{ng} / \mathrm{kg}$ body weight (Hazardous Substances Data Bank 2009) is equivalent to a dose of $35 \mu \mathrm{g}$ for a $70-\mathrm{kg}$ reference man. If all of this mass is absorbed through the skin with $100 \%$ efficiency, then the mass collected in the permeation cell collection solvent should not exceed $35 \mu \mathrm{g}$ during $8 \mathrm{~h}$. Clearly, Safeskin permeations with hexane collection exceed this threshold, but the water collections and all of the Solvex permeations did not. Because the normalized breakthrough time threshold of $250 \mathrm{ng} / \mathrm{cm}^{2}$ was exceeded, hexane was not a valid solvent for Safeskin gloves for 4- and 8-h exposures times in the solid-formulation challenges, nor was it valid for 8-h exposure in the aqueous emulsion challenges. Similarly, hexane was a valid 8-h collection solvent for Solvex gloves in solid-formulation challenges but not for 8-h aqueous emulsion challenges. Water was a valid collection solvent for all challenges, although permeation of dichlobenil was usually detected.

\section{Conclusion}

Permeation of the herbicide dichlobenil from both concentrated aqueous emulsion and dry solid Casoron $4 \mathrm{G}$ through disposable and chemically protective nitrile gloves is reported here for the first time. The permeation results differ with collection solvent, with the amount for water collection being much lower than for hexane collection. The chemically protective glove was permeated the least for each solvent. Hexane was not an adequate collection solvent relative to water for the disposable nitrile glove during 4- or 8-h or for 8-h aqueous emulsion challenges. Hexane solvent was adequate in solid-formulation challenges for the chemically protective glove during $8 \mathrm{~h}$, but not for the 8 -h aqueous emulsion challenge. The possible mechanisms to account for the observations were discussed in the previous text.

Acknowledgements This project was funded by the UCLA Center for Occupational and Environmental Health and National Institute for Occupational Safety and Health Grant No. OH03754.

Open Access This article is distributed under the terms of the Creative Commons Attribution Noncommercial License which permits any noncommercial use, distribution, and reproduction in any medium, provided the original author(s) and source are credited.

\section{References}

Ansell Occupational Healthcare (2007) Chemical resistance guide, 8th edn. Ansell, Coshocton

American Society for Testing and Materials (ASTM) (2004) Standard test method for resistance of protective clothing materials to permeation by liquids or gases under conditions of continuous contact, ASTM method F739-99a. In: Annual book of ASTM standards, vol 11. ATSM, West Conshohocken, pp 1299-1309

Chao KP, Lai JS, Lin HC (2007) Comparison of permeation resistance of protective gloves to organic solvents with ISO, ASTM, and EN standard methods. Polym Test 26:1090-1099

Fricker CM, Hardy JK (1992) Protective glove material permeation by organic solids. Am Ind Hyg Assoc J 53:745-750

Fricker CM, Hardy JK (1994) The effect of an alternate environment as a collection medium on the permeation characteristics of solid organics through protective glove materials. Am Ind Hyg Assoc J 55:738-742

Henry NW III, Stull JO (2003) Test methods and standards. In: Anna DH (ed) Chemical protective clothing, 2nd edn. AIHA Press, Fairfax, pp 175-268

Hazardous Substances Data Bank (HSDB) (2009) Dichlobenil. Available at http://www.toxnet.nlm.nih.gov/cgi-bin/sis/search

Ley EE, Bunge AL (2007) Chemical transport in silicone rubber membranes from pure powders and saturated aqueous solutions. J Memb Sci 292:35-44

McCarley KD, Bunge AL (2003) Absorption into silicone rubber membranes from powders and aqueous solutions. Int $\mathrm{J}$ Pharm 250:169-180

Mellstrom GA, Carlsson B, Boman AS (1994) Testing of protective effect against liquid chemicals. In: Mellstrom GA, Wahlberg JE, Maibach HI (eds) Protective gloves for occupational use. CRC Press, Boca Raton, pp 53-77

Parks JM, Cleek RL, Bunge AL (1997) Chemical release from topical formulations across synthetic membranes: infinite dose. J Pharm Sci $86: 187-192$

Reyes RM (2002) Chemical permeation data purple nitrile. KimberlyClark, San Diego

Romonchuk WJ, Bunge AL (2006) Permeation of 4-cyanophenol and methyl paraben from powder and saturated aqueous solution through silicone rubber membranes and human skin. J Pharm Sci 95:2526-2533

United States Environmental Protection Agency (USEPA) (2008) Dichlobenil: pesticide tolerances. Fed Regist 73(167):50563-50570 